\title{
Correction to: Active biomonitoring of atmospheric pollution in the Western Cape (South Africa) using INAA and ICP-MS
}

\author{
N. B. Ndlovu ${ }^{1,2}\left(\right.$ D) M. V. Frontasyeva ${ }^{3} \cdot$ R. T. Newman ${ }^{1} \cdot$ P. P. Maleka ${ }^{2}$
}

Published online: 13 November 2019

๑) Akadémiai Kiadó, Budapest, Hungary 2019

\section{Correction to: Journal of Radioanalytical and Nuclear Chemistry https://doi.org/10.1007/s10967-019-06823-z}

The article "Active biomonitoring of atmospheric pollution in the Western Cape (South Africa) using INAA and ICP-MS", written by "N. B. Ndlovu, M. V. Frontasyeva, R. T. Newman and P. P. Maleka", was originally published electronically on the publisher's Internet portal https://link.sprin ger.com/article/10.1007/s10967-019-06823-z on 10 October 2019 with open access. With the author(s)' decision to step back from Open Choice, the copyright of the article changed on 12 November 2019 to @ Akadémiai Kiadó, Budapest, Hungary 2019, and the article is forthwith distributed under the terms of copyright.

The original article has been corrected.

Publisher's Note Springer Nature remains neutral with regard to jurisdictional claims in published maps and institutional affiliations.

The original article can be found online at https://doi.org/10.1007/ s10967-019-06823-z.

N. B. Ndlovu

nbndlovu@tlabs.ac.za

1 Department of Physics, Stellenbosch University, Merriman Avenue, Matieland, Stellenbosch 7602, South Africa

2 Department of Subatomic Physics, iThemba LABS, Old Faure Road, Faure, Cape Town 7131, South Africa

3 Sector of Neutron Activation Analysis and Applied Research, Joint Institute for Nuclear Research, Joliot-Curie 6, Dubna, Moscow Region, Russia 141980 